\title{
BRPKM
}

Buletin Riset Psikologi dan Kesehatan Mental

http://e-journal.unair.ac.id/index.php/BRPKM e-ISSN: 2776-1851

\section{Pengaruh Kepribadian Proaktif dan Budaya Organisasi terhadap Perilaku Kerja Inovatif Pelaku Industri Pariwisata Jawa Timur}

\author{
MUHAMMAD SABILUL FIRDAUS \& SEGER HANDOYO* \\ Fakultas Psikologi Universitas Airlangga
}

\begin{abstract}
ABSTRAK
Penelitian ini bertujuan mengetahui adanya pengaruh kepribadian proaktif dan budaya organisasi terhadap perilaku kerja inovatif pelaku industri pariwisata Jawa Timur. Penelitian ini diikuti oleh 88 partisipan berusia 20-50 tahun. Metode penelitian yang digunakan adalah penelitian survei dengan menyebarkan kuesioner secara daring dan luring. Pendekatan kuantitatif digunakan dalam penelitian ini. Data dianalisis menggunakan bantuan program Jamovi 1.1.9.0. Hasil analisis data menunjukkan bahwa ada pengaruh positif kepribadian proaktif dan budaya organisasi terhadap pelaku industri pariwisata Jawa Timur dengan besar pengaruh $\mathrm{R}^{2}$ sebesar 0,469 .
\end{abstract}

Kata kunci: budaya organisasi, industripariwisata, kepribadian proaktif, perilaku kerja inovatif

\section{ABSTRACT}

This study aimed to determine the impact of proactive personality and organizational culture on innovative work behavior of East Java tourism industry actors. This study was followed by 88 participants aged 20-50 years. The research method used was survey research by distributing questionnaires online and offline. The subjects in this study were tourism industry employees in East Java. The quantitative approach used in this study. Data were analyzed using the help of Jamovi 1.1.9.0. program. The results of data analysis show that there is positive effect in proactive personality and oganizational culture towards innovative work behavior East Java tourism industry actors with a large effect of $R^{2}$ of 0.469 .

Keywords: innovative workbehavior, organizational culture, proactive personality, tourism industry

Buletin Penelitian Psikologi dan Kesehatan Mental (BRPKM), 2021, Vol. 1(2), 1468-1477

*Alamat korespondensi: Fakultas Psikologi Universitas Airlangga, Kampus B Universitas Airlangga Jalan Airlangga 4-6 Surabaya 60286. Surel: seger.handoyo@psikologi.unair.ac.id

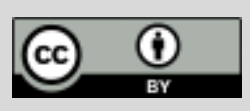

Naskah ini merupakan naskah dengan akses terbuka dibawah ketentuan the Creative Common Attribution License (CC-BY-4.0) (http://creativecommons.org/licenses/by/4.0), sehingga penggunaan, distribusi, reproduksi dalam media apapun atas artikel ini tidak dibatasi, selama sumber aslinya disitir dengan baik. 


\section{PEN D A H U L U A N}

Revolusi industri 4.0 membuat teknologi semakin canggih. Pekerjaan-pekerjaan yang dulu dilakukan oleh manusia kini tergantikan oleh mesin. Dampak kecanggihan teknologi sudah dirasakan ke seluruh sektor industri, termasuk pada industri pariwisata. Kalau dulu ketika ingin berwisata maka ada beberapa proses yang harus dilakukan, mulai dari memesan tiket penginapan, destinasi wisata, sampai dengan memesan tiket transportasi dan semuanya harus dilakukan jauh-jauh hari. Namun, kini semua proses tersebut bisa dilakukan dalam satu waktu, bahkan beberapa jam sebelum keberangkatan apabila dimungkinkan. Pekerjaan sebagai pemandu wisata kini telah tergantikan oleh pemandu wisata berbasis aplikasi (Nugroho dkk., 2016). Situasi ini harus menjadi perhatian bersama karena pariwisata tidak dapat dipisahkan dari kehidupan manusia terutama pada aktivitas sosial dan ekonomi. Pariwisata di Indonesia merupakan salah satu sektor industri yang mengalami pertumbuhan cukup pesat. Pada tahun 2018 The World Travel \& Tourism Council (WTTC), sebuah lembaga yang bergerak di bidang industri travel dan pariwisata dunia yang bermarkas di London menempatkan Indonesia di posisi ke-9 sebagai negara yang paling berhasil dalam mempercepat pertumbuhan pariwisata, posisi ini menjadi yang terbaik di Asia Tenggara (Poerwanto, 2018). Laporan The Travel \& Tourism Competitiveness Report yang dihasilkan dari Forum Ekonomi Dunia (WEF) Tahun 2019 menyebutkan adanya peningkatan indeks daya saing pariwisata Indonesia dari peringkat 42 di tahun 2017 menjadi 40 di Tahun 2019 (Prodjo, 2019).

Salah satu daerah yang menjadi tujuan utama wisata Indonesia, yaitu Provinsi Jawa Timur. Salah satu potensi pariwisata Jawa Timur yang sangat menjanjikan, yaitu Blue Fire yang berada di kawasan Kawah Ijen serta Pulau Gili Iyang yang berada di wilayah Sumenep memiliki kadar oksigen terbaik kedua di Dunia. Namun berdasarkan data dari Badan Pusat Statistik Provinsi Jawa Timur, pada bulan Agustus 2019 terjadi penurunan angka kunjungan Wisatawan Mancanegara (Wisman) yang masuk melalui Bandara Juanda sebesar 12,92 persen dibandingkan dengan periode yang sama tahun 2018 yang mencapai 34.166 kunjungan. Pada Tingkat Penghunian Kamar (TPK) hotel berbintang juga mengalami penurunan 5,59 persen dibandingkan dengan bulan Agustus tahun 2018. Pada tahun 2020, tantangan dalam menghadapi era disrupsi bagi industri pariwisata kini bertambah akibat adanya pandemi Covid19. Kondisi ini membuat pemerintah menerapkan kebijakan Pembatasan Sosial Berskala Besar (PSBB) sebagai upaya pencegahan dan pengendalian Covid-19. Akibatnya kunjungan wisatawan baik domestik maupun mancanegara mengalami penurunan.

Laporan Badan Pusat Statistika (BPS) Jawa Timur menyebutkan tahun 2020 sebagai tahun kunjungan wisata Jatim terendah dalam kurun tiga tahun terakhir. Pada periode Januari-Agustus 2020 penururnan jumlah kunjungan wisman ke Jawa Timur mencapai 78,44 persen dibandingkan dengan periode yang sama tahun 2019. Beberapa industri pariwisata seperti hotel dan restauran bahkan harus menghentikan operasional untuk sementara waktu hingga memilih untuk tutup permanen. Pemerintah sebagai pemangku kepentingan telah mengambil kebijakan dalam menghadapi dampak pandemi covid19 dengan memberikan stimulus terhadap pelaku industri pariwisata (Syarief, 2020). Kebijakan tersebut harus juga diimbangi dengan langkah kongkret pelaku industri dengan membuat suatu inovasi. Namun ada tantangan yang dihadapi dalam mendorong sumber daya manusia Indonesia agar mampu melakukan inovasi. Global Innovation Index, sebuah lembaga pemeringkatan indeks inovasi di setiap negara menempatkan Indonesia pada posisi ke-85 (Gunawan, 2019). Posisi ini lebih rendah dibandingkan dengan negara ASEAN lain seperti Singapura, Malaysia, Vietnam, Thailand, Filipina, dan Brunei Darussalam. Sebagai negara dengan potensi wisata terbaik dunia, seharusnya Indonesia lebih bisa mengembangkan inovasi agar mampu bersaing di tingkat global. Penelitian yang dilakukan oleh Getz dan Robinson (2003) menghasilkan bahwa 80\% penyebab meningkatnya inovasi pada organisasi 
merupakan ide-ide baru yang berasal dari karyawan, sedangkan 20\% sisanya berasal dari aktivitas yang direncanakan oleh organisasi. Inovasi yang dilakukan karyawan atau level individu disebut sebagai perilaku kerja inovatif atau innovative work behavior.

Perilaku kerja inovatif yaitu pengembangan ide yang dilakukan secara sengaja mulai dari pengenalan hingga penerapan ide-ide sebagai bagian dari peran dalam suatu pekerjaan (Momeni dkk., 2014). Kleysen dan Street (2001) memaparkan bahwa perilaku kerja inovatif adalah segala tindakan individu yang ditujukan untuk memunculkan, mengenalkan, dan menerapkan hal baru berupa pengembangan ide atau teknologi baru yang bisa menguntungkan pribadi, kelompok, maupun organisasi. Patterson dkk. (2009) membedakan faktor penyebab munculnya perilaku kerja inovatif menjadi dua, individu dan lingkungan kerja. Faktor yang berasal dari individu terdiri dari kemampuan kognitif, kepribadian, pengetahuan, mood, emosi, faktor perkembangan, dan motivasi. Faktor yang berasal dari lingkungan kerja meliputi organizational ambidexterity, karakteristik pemimpin, karakteristik rekan kerja, social network, struktur organisasi, dan budaya organisasi.

Salah satu faktor yang berasal dari dalam diri individu dalam mempengaruhi munculnya perilaku kerja inovatif adalah kepribadian proaktif. Penelitian yang dilakukan oleh Windiarsih dan Etikariena (2018) pada 135 karyawan salah satu Badan Usaha Milik Negara menghasilkan bahwa karyawan yang memiliki kepribadian proaktif tinggi cenderung akan menampilkan perilaku kerja inovatif. Karyawan BUMNyang menampilkan perilaku kerja inovatif diawali adanya inisiatif untuk memanfaatkan peluang yang bermuara pada adanya perubahan lingkungan kerja menjadi lebih efektif dan efisien sehingga memberikan dampak positif bagi diri pribadi dan organisasi. Penelitian yang dilakukan oleh Khasanah dan Himam (2019) dengan judul "Kepemimpinan Transformasional, Kepribadian Proaktif, dan Desain Kerja sebagai Prediktor Perilaku Kerja Inovatif” menghasilkan bahwa kepribadian proaktif dianggap sebagai prediktor dalam meningkatkan perilaku kerja inovatif karyawan yang berada pada posisi pengembangan manajemen. Individu dengan keribadian proaktif tinggi akan berusaha menemukan solusi atas masalah dan tantangan yang dihadapi melalui inovasi baru. Selain faktor dari dalam individu, perilaku kerja inovatif juga dipengaruhi oleh faktor kontekstual atau lingkungan organisasi.

Ketika ingin memahami perilaku kerja inovatif, dibutuhkan kombinasi antara faktor individul dan faktor kontekstual (Windiarsih \& Etikariena, 2018). Hasil meta-analisis yang dilakukan Damanpour (1991 dalam Matinaro \& Liu, 2017) menyebutkan ada sepuluh elemen organisasi yang memengaruhi munculnya inovasi, salah satunya yang signifikan, yaitu budaya. Budaya akan berpengaruh pada bagaimana individu dalam suatu kelompok memahami dan merespon lingkungannya (Schein, 1996). Setiap organisasi memiliki nilai dan tujuan yang dijadikan dasar dalam menjalankan roda organisasi. Penelitian yang dilakukan oleh Eskiler, dkk. (2016) dengan judul "The Relationship between Organizational Culture and Innovative Work Behavior for Sports Services in Tourism Enterprises" menghasilkan bahwa empat sub-dimensi dari budaya organisasi mempunyai hubungan yang signifikan terhadap perilaku kerja inovatif karyawan. Beberapa penelitian telah membuktikan bahwa budaya organisasi mempunyai pengaruh terhadap perilaku kerja inovatif. Namun, penelitian yang dilakukan oleh Fahrurrobi dkk. (2020) dengan judul "Pengaruh Kepemimpinan Transformasional dan Budaya Organisasi terhadap Perilaku Kerja Inovatif Guru di SMA Swasta Se-Kecamatan Pamijahan Bogor" menghasilkan bahwa budaya organisasi tidak memiliki pengaruh terhadap perilaku kerja inovatif. Hasil yang tidak konsisten pada penelitian budaya organisasi perlu menjadi pertimbangan agar dilakukan penelitian kembali. Penelitian terdahulu telah menemukan faktor-faktoryang mempengaruhi perilaku kerja inovatif, baik yang berasal dari individu maupun lingkungan organisasi. Namun, belum ada penelitian yang mencoba melihat pengaruh kepribadian proaktif dan budaya organisasi terhadap perilaku kerja inovatif pada sektor industri pariwisata Jawa Timur. Creswell (dalam Azwar, 2017) 
menyebutkan bahwa penelitian yang sudah dilakukan kemudian diulang namun dengan subjek dan lokasi yang berbeda akan memperluas generalisasi hasilnya.

Berdasarkan penjelasan tersebut, dalam penelitian ini penulis ingin mengetahui pengaruh kepribadian proaktif dan budaya organisasi terhadap perilaku kerja inovatif pelaku industri pariwisata Jawa Timur.

\section{Perilaku Kerja Inovatif}

Sejak 1980-an, banyak ilmuwan telah menaruh perhatian pada tingkat inovasi individu. Tidak seperti inovasi tingkat organisasi atau tim, inovasi individu adalah sejauh mana karyawan menghasilkan, menyebarkan, dan menerapkan ide-ide baru di tempat kerja. Perilaku kerja yang inovatif telah diistilahkan sebagai fenomena dinamis dan multifaset yang juga mencakup kreativitas. Ini terdiri dari empat atribut yang saling terkait, yaitu, pengakuan masalah, pembuatan konsep, promosi, dan pengakuan (Khan dkk., 2020). Perilaku kerja inovatif atau innovative work behaviour adalah segala perilaku individu yang mengarahkan pada pemunculan, pengenalan, dan penerapan kebaruan yang memiliki manfaat pada setiap tingkat organisasi (Kleysen \& Street, 2001). Terdapat lima dimensi untuk mengukur perilaku kerja inovatif, yaitu opportunity exploration, generativity, formative investigation, championing, application.

\section{Kepribadian Proaktif}

Kepribadian proaktif didefinisikan sebagai sikap individu yang berorientasi pada keuntungan, berinisiatif, berani melakukan sesuatu secara tekun, dan bertanggung jawab atas apa telah dilakukan sampai menghasilkan perubahan pada lingkungannya (Seibert dkk., 1999). Individu yang memiliki kepribadian proaktif akan melakukan inisiatif guna memperbaiki kondisi saat ini (status quo) atau menciptakan sesuatu yang baru. Karakteristik individu proaktif ditunjukkan melalui perilaku yang mampu mengarahkan diri sendiri, memiliki orientasi pada masa depan, serta mampu memberikan perubahan terhadap diri sendiri maupun lingkungan.

\section{Budaya Organisasi}

Khan, dkk. (2020) mendefinisikan budaya organisasi sebagai proses perilaku, nilai, keyakinan, dan kebiasaan yang mengarahkan perilaku individu dalam suatu organisasi. Budaya memungkinkan para pemimpin untuk melihat perilaku tertentu yang harus menjadi teladan dan mengajari karyawan bagaimana berperilaku. Dengan kata lain, budaya organisasi adalah sistem nilai dan keyakinan yang membentuk perilaku karyawan dalam suatu organisasi (Eskiler dkk., 2016). Selanjutnya, Chang dan Lin (2007) menjelaskan bahwa terdapat empat karakteristik budaya organisasi, yaitu cooperativeness, innovativeness, consistency, dan effectiveness.

\section{Pelaku Industri Pariwisata Jawa Timur}

Damanik \& Weber (2006) mengatakan bahwa industri pariwisata adalah segala usaha yang menghasilkan barang atau jasa bagi pariwisata. Industri pariwisata adalah kumpulan usaha pariwisata yang saling terkait dalam rangka menghasilkan barang dan atau jasa bagi pemenuhan kebutuhan wisatawan dalam penyelenggaraan pariwisata (UU Kepariwisataan, 2009). Damanik \& Weber (2006) mengelompokkan usaha pariwisata ke dalam dua golongan yaitu pelaku langsung dan pelaku tidak langsung. Pelaku langsung adalah usaha-usaha wisata yang melakukan penawaran langsung kepada wisatawan sehingga jasanya dibutuhkan wisatawan secara langsung. Pelaku tidak langsung adalah usaha yang khusus menghasilkan produk yang secara tidak langsung berkontribusi untuk mendukung pariwisata. 
Berdasarkan penjelasan terkait perilaku kerja inovatif, kepribadian proaktif, dan budaya organisasi maka hipotesis pada penelitian ini sebagai berikut:

$\mathrm{H}_{0}$ : Tidak ada pengaruh kepribadian proaktif dan budaya organisasi terhadap perilaku kerja inovatif pelaku industry pariwisata Jawa Timur.

$\mathrm{H}_{1}$ : Terdapat pengaruh pengaruh kepribadian proaktif dan budaya organisasi terhadap perilaku kerja inovatif pelaku industry pariwisata Jawa Timur.

\section{Desain Penelitian}

\section{E T O D E}

Berdasarkan pendekatan metodologisnya, penelitian ini termasuk jenis penelitian kuantitatif. Metode kuantiatif menitikberatkan analisisnya pada data-data berupa angka (kuantitatif) yang dikumpulkan melalui prosedur pengukuran serta diolah menggunakan metode analisis statistika (Azwar, 2017). Apabila dilihat berdasarkan taraf penjelasan yang dihasilkan, penelitian ini termasuk penelitian eksplanasi yang berusaha untuk menjelaskan beberapa realitas yang ada di masyarakat. Sedangkan berdasarkan waktu pelaksanaannya, penelitian ini termasuk dalam penelitian cross sectional yaitu melakukan pengumpulan data pada satu waktu tertentu atau bersamaan.

\section{Partisipan}

Penelitian ini dilaksanakan di wilayah Provinsi Jawa Timur. Partisipan pada penelitian yaitu individu pelaku industri pariwisata yang bekerja sebagai karyawan (memiliki atasan) pada bidang industri pariwisata. Penelitian ini menggunakan teknik sampling purposive sampling dalam non probability sampling yaitu siapapun yang masuk ke dalam kriteria partisipan memiliki kesempatan yang sama untuk menjadi sampel. Pengisian kuesioner diawali dengan persetujuan partisipan dengan mengisi informed consent kemudian dilanjutkan dengan pengisian kuesioner alat ukur.

Penelitian ini diikuti oleh 88 partisipan (47,7\% laki-laki; 52,3\% perempuan). Partisipan yang mendominasi pada penelitian ini memiliki rentang usia 20-30 tahun $(54,5 \%)$, kemudian bidang industri pariwisata yang memiliki persentase tertinggi yaitu daya tarik wisata sebanyak 34 partisipan $(38,6 \%)$.

\section{Pengukuran}

Pada penelitian ini terdapat tiga alat ukur yang digunakan. Pertama, variabel perilaku kerja inovatif diukur dengan menggunakan skala yang dikembangkan oleh Kleysen dan Street (2001) berisi 14 aitem dan terdiri atas lima dimensi, yaitu menciptakan ide (idea exploration), menyempurnakan ide (formative suggestion), mengembangkan ide (generativity), mencari dukungan (championing), serta mengaplikasikan ide (application). Skala memiliki enam pilihan jawaban (tidak pernah, hampir tidak pernah, kadang-kadang, cukup sering, sangat sering, selalu) dengan tingkat reliabilitas $(\alpha=.95)$. Partisipan yang mempunyai skor lebih tinggi memiliki kecenderungan yang lebih tinggi untuk menampilkan perilaku kerja inovatif di tempat kerjanya. Pada variabel kepribadian proaktif diukur dengan menggunakan skala Proactive Personality Scale milik Seibert dkk. (1999) yang berisi sepuluh aitem dengan tujuh pilihan jawaban (sangat tidak setuju, tidak setuju, agak tidak setuju, netral, agak setuju, setuju, sangat setuju) dengan tingkat reliabilitas $(\alpha=.84)$. Partisipan yang memberikan respon yang lebih mendukung terhadap aitem-aitem dalam skala maka dia cenderung memiliki tingkat proaktif yang lebih tinggi. Pengukuran budaya organisasi menggunakan alat ukur yang dikembangan oleh Chang dan Lin (2007) yang berisi 26 aitem menggunakan model likert dengan lima pilihan jawaban (sangat tidak setuju, tidak setuju, ragu-ragu/netral, setuju, sangat setuju). Partisipan yang memberikan respon 
yang lebih mendukung terhadap aitem-aitem dalam skala menandakan tempat dia bekerja memiliki budaya organisasi yang berkaitan dengan dimensi pada skala ini yaitu cooperative culture, innovativeness, consistency, dan effectiveness. Masing-masing alat ukur tersebut telah dilakukan uji validitas dengan teknik content validity oleh tiga professionaljudgement.

\section{Analisis Data}

Data pada penelitian ini diolah dengan menggunakan software Jamovi versi 1.1.9.0. Analisis data dalam penelitian ini menggunakan teknik analisis regresi linear berganda yang sebelumnya dilakukan uji asumsi. Uji asumsi yang digunakan dalam penelitian ini yaitu uji normalitas, uji linearitas, uji multikolinearitas, analisis residual, uji homoskedastisitas serta deteksi outlier dan mendapatkan hasil bahwa telah terpenuhinya semua uji asumsi.

\section{H A S I L P E N E LI T I A N}

Analisis deskriptif dalam penelitian ini memperoleh hasil bahwa sebanyak 88 menjadi partisipan. Skor rata-rata variabel kepribadian proaktif adalah 52,9 dengan nilai minimum 30, maximum 70, dan standar deviasi 8,69. Pada variabel budaya organisasi skor rata-rata sebesar 106 dengan nilai minimum 54, maximum 130, dan standar deviasi 14,7. Selanjutnya, untuk variabel perilaku kerja inovatif didapatkan rata-rata sebesar 62 dengan nilai minimum 20, maximum 84, dan standar deviasi 14,8.

Sebelum melakukan analisis regresi berganda, penulis terlebih dahulu melakukan analisis regresi sederhana. Analisis pertama yaitu melihat seberapa besar pengaruh budaya organisasi terhadap perilaku kerja inovatif. Berdasarkan hasil analisis diperoleh hasil bahwa varians dari budaya organisasi dapat menjelaskan varians dari perilaku kerja inovatif sebesar $37,7 \%\left(F(86)=52,2 ; p<, 001 ; R^{2}=0,377\right)$. Analisis kedua yaitu melihat pengaruh kepribadian proaktif terhadap perilaku kerja inovatif. Berdasarkan hasil analisis memperoleh hasil bahwa varians dari kepribadian proaktif dapat menjelaskan varians dari perilaku kerja inovatif sebesar 28,6\% $\left(F(86)=34,4 ; p<, 001 ; R^{2}=0,286\right)$. Pada analisis analisis regresi berganda penulis menggunakan dua model. Model pertama melihat pengaruh budaya organisasi terhadap perilaku kerja inovatif. Model yang kedua penulis ingin mengetahui apakah ada perubahan signifikan yang terjadi pada model ketika menambahkan satu prediktor yaitu kepribadian proaktif. Berdasarkan hasil analisis diperoleh hasil bahwa varians dari kepribadian proaktif dan budaya organisasi dapat menjelaskan varians dari perilaku kerja inovatif sebesar 46,9\% dan ada peningkatan sebesar 9,2\% ketika menambahkan satu prediktor kepribadian proaktif $\left(F(85)=37,5 ; p<, 001 ; R^{2}=0,469\right)$. Pada regresi linear ini juga didapatkan data intercept, slopes, dan residual atau error untuk menggambarkan nilai perkiraan variabel Y. Persamaan garis regresi yang dihasilkan yaitu $Y^{\prime}=-18,584+(0,568) \mathrm{X} 1+(0,475) \mathrm{X} 2+$ e. Dengan demikian, kepribadian proaktif dan budaya organisasi merupakan prediktor yang dapat menjelaskan perilaku kerja inovatif. Sehingga $\mathrm{H}_{0}$ pada penelitian ini ditolak dan $\mathrm{H}_{\mathrm{a}}$ penelitian dapat diterima.

\section{I S K U S I}

Penelitian ini bertujuan untuk mengetahui pengaruh kepribadian proaktif dan budaya organisasi terhadap perilaku kerja inovatif pelaku industri pariwisata Jawa Timur. Uji analisis memperoleh hasil bahwa kepribadian proaktif dan budaya organisasi memiliki pengaruh terhadap perilaku kerja inovatif. Berdasarkan nilai $R$ square dapat dilihat bahwa variabel kepribadian proaktif dan budaya organisasi secara bersamaan mampu memprediksi perilaku kerja inovatif sebesar 0,469. Nilai 0,469 mempunyai arti kepribadian proaktif dan budaya organisasi mengalami overlap dan mampu memprediksikan secara 
bersamaan sebesar 46,9\% terhadap variabel perilaku kerja inovatif. Sedangkan sisanya sebesar 53,1\% dipengaruhi oleh variabel lain yang tidak dijelaskan pada penelitian.

Hasil penelitian ini memiliki kesesuaian dengan penelitian yang dilakukan oleh Esha dan Dwipayani (2020) pada 63 karyawan PT Smart Meter Indonesia yang menghasilkan bahwa budaya organisasi berpengaruh terhadap perilaku kerja inovatif. Karyawan akan mendapatkan kepuasaan dan berpegang teguh pada komitmennya ketika nilai-nilai yang mereka yakini sesuai dengan nilai-nilai yang ada di perusahaan (Schein, 1996). Perusahaan yang memiliki budaya organisasi yang kuat biasanya akan memiliki manajemen yang kuat (Li-Ping Tang dkk., 2000). Budaya inovatif menghasilkan kolektivisme dalam kelompok di antara individu dengan menghasilkan suasana yang menantang pemikiran dan gagasan (Khan dkk., 2020). Inovasi di internal perusahaan sangat dibutuhkan, namun tanpa ada budaya, struktur, dan strategi bagaimana melakukannya menyebabkan inovasi sulit muncul di suatu organisasi (Matinaro \& Liu, 2017). Hasil analisis per dimensi budaya organisasi menunjukkan bahwa semua dimensi memiliki pengaruh pada perilaku kerja inovatif. Penulis memiliki asumsi alasan yang membuat budaya organisasi memiliki pengaruh yang lebih besar daripada kepribadian proaktif dalam memprediksi perilaku kerja inovatif pelaku industri pariwisata Jawa Timur. Salah satunya dipengaruh i oleh data sebaran demografis partisipan penelitian yang didominasi oleh mereka yang memiliki pengalaman kerja lebih dari empat tahun. Mereka yang bekerja lebih dari empat tahun diasumsikan memiliki pemahaman dan kemampuan yang kuat untuk menginternalisasi nilai-nilai dalam organisasi.

Selain faktor yang berasal dari organisasi atau kontekstual, perilaku kerja inovatif juga dipengaruhi oleh faktor individu, salah satunya kepribadian proaktif. Hasil penelitian ini memperkuat penelitian yang dilakukan Pons dkk. (2016) yang memperoleh hasil bahwa kepribadian proaktif menjadi faktor utama yang berpengaruh terhadap perilaku kerja inovatif. Adanya hubungan positif kepribadian proaktif dengan perilaku kerja inovatif disebabkan oleh individu dengan kepribadian proaktif yang tinggi mempunyai kecenderungan untuk memiliki motivasi yang tinggi pula ketika mengambil inisiatif dan merespon situasi yang sedang dihadapi di lingkungannya. Individu yang memiliki kepribadian proaktif akan rela berusaha merubah lingkungannya dengan cara aktif dalam menunjukkan inisiatif, melihat kesempatan yang ada dan memanfaatkannya (Windiarsih \& Etikariena, 2018). Individu dengan kepribadian proaktif akan bertindak melalui aktualisasi keadaan hati atau tanda munculnya masalah, sedangkan individu yang lebih memilih untuk berhati-hati dalam melihat suatu keadaan akan menantikan informasi atau kesempatan untuk melakukan sesuatu. Ketekunan individu proaktif membuat mereka lebih efektif ketika mengemukakan ide-ide yang dimiliki dan menghasilkan dukungan ketika mempromosikan implementasi ide supaya sukses (Schwaab, dkk., dalam Khasanah \& Himam, 2019). Inovasi akan muncul ketika individu memiliki sikap yang tidak anti terhadap perubahan. Sikap tersebut bisa didapati ketika individu memiliki kepribadian proaktif.

Individu yang proaktif akan tetap teguh pada keinginan untuk mengubah lingkungan sekitarnya meskipun pada situasi yang memaksa. Hal ini diharapkan dapat menjadi semangat baru di situasi pandemi saat ini, meskipun dengan berbagai kebijakan yang mengharuskan industri pariwisata tetap mematuhi protokol kesehatan yang ketat namun pelaku industri pariwisata harus mampu melakukan inovasi agar pengunjung tetap merasa nyaman ketika berwisata. Karyawan yang memiliki kepribadian proaktif diharapkan mendapatkan dukungan dari budaya organisasi sehingga terjadi akselerasi dalam memunculkan perilaku kerja inovatif. 


\section{S I M P U L A N}

Berdasarkan hasil analisis data yang telah dilakukan dapat diambil kesimpulan bahwa kepribadian proaktif dan budaya organisasi memiliki pengaruh yang signifikan terhadap perilaku kerja inovatif pelaku industri pariwisata Jawa Timur. Penelitian selanjutnya diharapkan lebih memperjelas bagian dari masing-masing divisi atau departemen di industri pariwisata karena ada kemungkinan masingmasing departemen atau divisi memiliki proporsi yang berbeda-beda dalam melakukan inovasi. Penelitian selanjutnya juga disarankan memperluas cakupan populasi dengan melakukan penelitian di daerah pariwisata lain, supaya bisa diperoleh generalisasi penelitian yang lebih komprehensif.

Bagi industri pariwisata diharapkan membuat kesepakatan dengan seluruh karyawan terkait nilai-nilai yang dimiliki oleh perusahaan. Mereka harus memiliki perspektif yang sama, kepercayaan bersama dan nilai-nilai komunal diantara anggota organisasi. Sehingga membantu karyawan dan pemimpin membuat keputusan yang konsisten dan berperilaku secara konsisten. Pengelola industri pariwisata juga bisa menjadikan kepribadian proaktif sebagai salah satu kriteria dalam melakukan rekrutmen pekerja. Hal ini diharapkan ketika individu memiliki kepribadian proaktif maka ada kemungkinan akan memunculkan perilaku kerja inovatif dan memberikan inovasi bagi perusahaan.

\section{UCAPAN TERIMAKASIH}

Penulis mengucapkan terima kasih kepada Allah SWT, keluarga, dosen, teman-teman, partisipan penelitian, dan pihak-pihak yang terlibat baik langsung maupun tidak dalam memastikan penelitian bisa terselesaikan.

\section{DEKLARASI POTENSI TERJADINYA KONFLIK KEPENTINGAN}

Muhammad Sabilul Firdaus dan Seger Handoyo tidak bekerja, menjadi konsultan, memiliki saham, atau menerima dana dari perusahaan atau organisasi manapun yang mungkin akan mengambil untung dari diterbitkannya naskah ini.

\section{PUSTAKA ACUAN}

Azwar, S. (2017). Metode Penelitian Psikologi Edisi 2. Pustaka Pelajar.

Damanik, J. \& Weber, H. F. (2006). Perencanaan Ekowisata: Dari Teori ke Aplikasi. Yogyakarta: PUSBAR UGM \& Andi Yogyakarta.

Esha, D., \& Dwipayani, W. (2020). Pengaruh Kepemimpinan dan Budaya Organisasi Terhadap Perilaku Kerja Inovatif di PT Smart Meter. Simposium Nasional Mulitidisiplin (SinaMu), 2. http://jurnal.umt.ac.id/index.php/senamu/article/view/3522

Eskiler, E., Ekici, S., Soyer, F., \& Sari, I. (2016). The Relationship between Organizational Culture and Innovative Work Behavior for Sports Services in Tourism Enterprises. Physical Culture and Sport. Studies and Research, 69(1), 53-64. https://doi.org/10.1515/pcssr-2016-0007 
Fahrurrobi, N., Ihsan, M., Rahmawati, I., \& Lestari, H. (2020). Pengaruh kepemimpinan transformasional dan budaya organisasi terhadap perilaku kerja inovatif guru di sma swasta se-kecamatan pamijahan bogor. Jurnal Sains Indonesia, 1(2), 99-105.

Getz, I., \& Robinson, A. G. (2003). Innovate or Die: Is that a Fact? Creativity and Innovation Management, 12(3), 130-136. https://doi.org/10.1111/1467-8691.00276

Gunawan, A. (2019, Juli 25). Duh, RI Jauh Tertinggal di Indeks Inovasi Global 2019. CNBC Indonesia. https://www.cnbcindonesia.com/news/20190725131051-4-87538/duh-ri-jauh-tertinggal-diindeks-inovasi-global-2019

Khan, M. A., Ismail, F. B., Hussain, A., \& Alghazali, B. (2020). The Interplay of Leadership Styles, Innovative Work Behavior, Organizational Culture, and Organizational Citizenship Behavior. SAGE Open, 10(1). https://doi.org/10.1177/2158244019898264

Khasanah, I. F. N., \& Himam, F. (2019). Kepemimpinan Transformasional Kepribadian Proaktif dan Desain Kerja sebagai Prediktor Perilaku Kerja Inovatif. Gadjah Mada Journal of Psychology (GamaJoP), 4(2), 143. https://doi.org/10.22146/gamajop.46361

Kleysen, R. F., \& Street, C. T. (2001). Toward a multi-dimensional measure of individual innovative behavior. Journal of Intellectual Capital, 2(3), 284-296. https://doi.org/10.1108/EUM0000000005660

Li-Ping Tang, T., Kim, J. K., \& O’Donald, D. A. (2000). Perceptions of Japanese organizational cultureEmployees in non-unionized Japanese-owned and unionized US-owned automobile plants. $\begin{array}{llll}\text { Journal of } & \text { Managerial } & \text { 5sychology, } & \text { 15(6), }\end{array}$ https://doi.org/10.1108/02683940010373383

Matinaro, V., \& Liu, Y. (2017). Towards increased innovativeness and sustainability through organizational culture: A case study of a Finnish construction business. Journal of Cleaner Production, 142, 3184-3193. https://doi.org/10.1016/j.jclepro.2016.10.151

Momeni, M., Ebrahimpour, H., \& Ajirloo, M. B. (2014). THE EFFECT OF EMPLOYEES' SELF-EFFICACY ON INNOVATIVE WORK BEHAVIOR AT SOCIAL SECURITY ORGANIZATION EMPLOYEES IN ARDABIL PROVINCE. Kuwait chapter of Arabian Journal of Business \& Management Review , 3(8), $29-32$.

Nugroho, T. B., Iqbal, M., \& Rohmah, Y. S. (2016). APLIKASI SISTEM PEMANDU WISATA DI KOTA CIREBON BERBASIS ANDROID. Jurnal Elektro dan Telekomunikasi Terapan, 1(1), 51. https://doi.org/10.25124/jett.v1i1.84

Patterson, P. F., Kerrin, D. M., \& Gatto-Roissard, G. (2009). Characteristics and behaviours of innovative people in organisations. Literature review prepared for the NESTA Policy \& Research Unit, 1-63. https://www.nesta.org.uk/report/characteristics-and-behaviours-of-innovative-people-inorganisations/ 
Poerwanto, E. (2018, Oktober). WTTC Masukan Pariwisata Indonesia dalam 10 Besar Dunia. Bisniswisata. https://bisniswisata.co.id/wttc-masukan-pariwisata-indonesia-dalam-10-besardunia/

Pons, F. J., Ramos, J., \& Ramos, A. (2016). Antecedent variables of innovation behaviors in organizations: Differences between men and women. European Review of Applied Psychology, 66(3), 117-126. https://doi.org/10.1016/j.erap.2016.04.004

Prodjo, W. A. (2019, September 9). Indeks Daya Saing Pariwisata Indonesia Tahun 2019 Naik Halaman all-Kompas.com. kompas.com. https://travel.kompas.com/read/2019/09/05/173751627/indeks-daya-saing-pariwisataindonesia-tahun-2019-naik?page=all

Schein, E. H. (1996). Culture: The Missing Concept in Organization Studies. Administrative Science Quarterly, 41(2), 229. https://doi.org/10.2307/2393715

Seibert, S. E., Crant, J. M., \& Kraimer, M. L. (1999). Proactive personality and career success. Journal of Applied Psychology, 84(3), 416-427.https://doi.org/10.1037/0021-9010.84.3.416

Syarief, I. S. (2020, Juli 16). Tiga Langkah Kadin Jatim Hidupkan Kembali Industri Pariwisata. suarasurabaya.net. https://www.suarasurabaya.net/ekonomibisnis/2020/tiga-langkah-kadinjatim-hidupkan-kembali-industri-pariwisata/

UU Kepariwisataan. (2009). UNDANG-UNDANG REPUBLIKINDONESIA NOMOR 10.TAHUN 2009.

Windiarsih, R., \& Etikariena, A. (2018). Hubungan Antara Kepribadian Proaktif dan Perilaku Kerja Inovatif di BUMN X. Journal Psikogenesis, 5(2), 123. https://doi.org/10.24854/jps.v5i2.501 